\title{
PROCESSOS ESTRUTURAIS E DIÁLOGOS INSTITUCIONAIS NO SUPREMO TRIBUNAL FEDERAL: UMA ANÁLISE DOS ARGUMENTOS JUDICIAIS NA ADPF $347^{1}$
}

\author{
STRUCTURAL LITIGATION AND CONSTITUTIONAL DIALOGUES ON THE
} BRAZILIAN SUPREME COURT: AN ANALYSIS OF THE JUDICIAL DECISION MAKING ON THE ADPF 347

Eduarda Peixoto da Cunha França Mestranda em Direito pela Universidade Federal de Pernambuco (UFPE). Graduada em Direito pela Universidade Católica de Pernambuco (UNICAP). Bolsista da Coordenação de Aperfeiçoamento de Pessoal de Nível Superior (CAPES). Recife/PE. E-mail: eduardacunhapf@gmail.com

\begin{abstract}
RESUMO: A declaração do Estado de Coisas Inconstitucional no sistema carcerário brasileiro pelo Supremo Tribunal Federal (STF) foi paradigmática do ponto de vista simbólico, considerando a abertura do Tribunal à apreciação dos chamados "litígios estruturais". Apesar disso, anos após a sua declaração, pouco ou nada mudou nas condições degradantes do sistema carcerário do país. O presente artigo busca analisar o discurso judicial na liminar proferida no caso da ADPF 347, com o intuito de investigar a presença de uma possível (in)disposição do ministro relator de engajar o STF em um diálogo institucional com as instâncias majoritárias e criar um ambiente cooperativo para a superação das falhas sistêmicas violadoras de direitos fundamentais. Para tanto, o trabalho será dividido em três partes, nas quais serão estudadas, respectivamente: a ideia de ativismo dialógico enquanto alternativa ao ativismo solipsista e à autocontenção judicial; duas teorias normativas que direcionam a postura jurisdicional frente à judicialização de questões estruturais; e, por fim, os argumentos do ministro relator no deferimento parcial da liminar na $\mathrm{ADPF}$ 347. A pesquisa é de cunho bibliográfico-documental com análise qualitativa de caso.
\end{abstract}

\footnotetext{
${ }^{1}$ Artigo recebido em 21/12/2020 e aprovado em 03/05/2021.
} 
PALAVRAS-CHAVE: Ativismo Judicial; Estado de Coisas Inconstitucional; Diálogos Institucionais; Processo Estrutural.

\begin{abstract}
The declaration of the Unconstitutional State of Things in the Brazilian prison system by the Supreme Federal Court (STF) was paradigmatic from a symbolic point of view, considering the opening of the Court to the appreciation of the so-called "structural litigation". Despite this, years after its declaration, little or nothing has changed in the degrading conditions of the country's prison system. This article seeks to analyze the judicial discourse in the preliminary injunction given in the case of ADPF 347, in order to investigate the presence of a possible (in)willingness of the court to engage itself in an constitutional dialogue with the political branches and create a cooperative environment to overcome systemic failures that violate fundamental rights. To this end environment to overcome systemic failures that violate fundamental rights. To this end, the work will be divided into three parts, in which they will be studied, respectively: the idea of dialogical activism as an alternative to solipsist activism and judicial self-restraint; two normative theories that guide the jurisdictional stance towards the judicialization of structural issues; and, finally, the arguments of the reporting minister in partially granting the preliminary injunction in ADPF 347. The research is bibliographic and documentary with qualitative analysis of the case.
\end{abstract}

KEYWORDS: Judicial Activism; Unconstitutional State of Things; Constitutional Dialogues; Structural Injunctions.

\title{
1. Introdução
}

Apesar de tratarem de questões relativas à alocação de bens escassos (justiça distributiva), a judicialização dos direitos sociais, econômicos e culturais (DESC), frequentemente, é feita de maneira individualizada, atomizada. Isso porque, apesar de serem direitos de todos, são, também, direitos de cada um. Sob este último enfoque, eles possuem estrutura de direito subjetivo e, portanto, uma vez violados, podem ser exigidos judicialmente por cada um de seus titulares. É o que garante, também, o direito fundamental da inafastabilidade da jurisdição (art. 5, XXXV da Constituição Federal de 1988). 
O amplo acesso à justiça - garantido pelo referido dispositivo - permitiu o surgimento da contradição intrínseca entre o tratamento atomizado dos direitos sociais e sua necessária e essencial universalização, dando ensejo a algumas consequências. A primeira delas é que as múltiplas decisões concessivas de direitos sociais podem vir a interferir no planejamento e execução de uma política pública em curso, na medida em que obrigam sua revisão e/ou adaptação para o cumprimento das ordens judiciais. A segunda é que o tratamento individualizado dessas questões, via de regra, não permite a discussão da política pública como um todo, mas somente da situação particular do autor, o que pode dar ensejo a decisões distantes da realidade do Poder Público, não passíveis de universalização, bem como transformar o Poder Judiciário em um gerador de desigualdades - como, por exemplo, aquelas que, baseando-se no direito constitucional à saúde, concedem aos autores de ações individuais medicamentos e insumos de alto valor que não constam nas listagens préestabelecidas pela Administração Pública com o intuito de atender à população. Assim, ao invés de promover a fruição, por todos, de bens coletivos, as decisões atomizadas privilegiam aqueles que vêm ao Judiciário demandar de forma individual a concretização do seu direito.

A discussão sobre a possibilidade de judicializar temas políticos no Brasil, dessa forma, talvez não seja tão importante como a discussão acerca das melhores formas de promover essa judicialização e superar as adversidades políticas, sociais e institucionais que comprometem o gozo efetivo dos DESC por seus titulares. As objeções suscitadas acerca da (i)legitimidade desse exercício ${ }^{2}$, apesar de importantes, não fomentam debates mais relevantes que aqueles preocupados em compreender os limites e possibilidades - práticos - da decisão judicial que busca concretizar direitos fundamentais, nem daqueles que buscam propor atuações dialógicas entre o sistema de justiça e a sociedade civil, pois enquanto as primeiras estão preocupadas com o "dever ser", os segundos procuram achar soluções imediatas, pautadas nas variáveis que a realidade impõe (e que, nem sempre, coadunam-se com o funcionamento ideal dos Poderes e demais atores sociais), bem como nas reais disposições dos atores envolvidos de cooperarem.

\footnotetext{
2 LIMA, Flavia Danielle Santiago; FRANÇA, Eduarda Peixoto da Cunha. Ativismo dialógico x bloqueios institucionais: limites e possibilidades do controle jurisdicional de políticas públicas a partir da Sentencia T025/04 da Corte Colombiana. Argumenta Journal Law, n. 31, p. 209-243, jul./dez., 2019, p.210-211.
} 
O impacto da judicialização dos direitos sociais no processo, dessa forma, é um importante fator a ser estudado. Isso porque a possibilidade de sua tutela pela via jurisdicional levou essa espécie de direito material, que possui determinadas especificidades, ao processo civil, interferindo diretamente em técnicas processuais tidas como adequadas, sobretudo quando se observa a possibilidade do enfrentamento dos chamados "litígios estruturais".

Nesse sentido, o presente trabalho analisa o Estado de Coisas Inconstitucional do sistema carcerário brasileiro para responder ao seguinte questionamento: é possível afirmar que os argumentos utilizados pelo ministro relator, na concessão parcial da liminar na ADPF 347, buscaram engajar o Supremo Tribunal Federal em um diálogo institucional com as instâncias majoritárias para a superação do Estado de Coisas Inconstitucional no sistema carcerário brasileiro?

Para tanto, o trabalho utilizará a metodologia bibliográfico-documental e será dividido em três partes. A primeira apresentará a ideia de ativismo dialógico, explicando a razão pela qual esta classificação de postura judicial apresenta-se como a mais adequada para superar as críticas à falta de legitimidade e expertise do Poder Judiciário ao tratar de litígios estruturais. A segunda, por sua vez, apresentará a teoria normativa desenvolvida pela jurista norte-americana, Susan Sturm, para sentenças estruturais, bem como da postura consequencialista, estratégica e mediadora do magistrado apresentada pela professora Susana Henriques da Costa. Os ideais expostos servirão como base para a análise da desenvoltura do Supremo Tribunal Federal (STF) no enfrentamento do Estado de Coisas Inconstitucional (ECI) do sistema carcerário brasileiro. Ao final, será realizada uma análise qualitativa do caso em questão, bem como apontadas possíveis razões pelas quais a judicialização de um caso notadamente estrutural não se desenvolveu em um processo estrutural, mantendo o status quo vigente nas penitenciárias do país.

\section{Possíveis caminhos para a construção democrática do processo estrutural: apresentação do ativismo dialógico}

Ao contrário daquilo que pode imaginar-se quando o dilema da justiciabilidade dos direitos sociais está em questão, existe uma alternativa da qual o Poder Judiciário pode se 
utilizar ao invés de apostar na autocontenção ou no ativismo solipsista: o ativismo dialógico ${ }^{3}$. O ativismo dialógico, é preciso ressaltar, consiste em um tipo ideal de postura judicial, que pode, em maior ou menor grau, ser condizente com a realidade. É, portanto, um conceito artificial e normativo, visto que a realidade em si é hipercomplexa e sujeita a subjetividades que dificilmente conseguem ser mapeadas. Entretanto, funciona como tipo ideal weberiano ${ }^{4}$ e foca em determinadas características da realidade - que podem ou não estar presentes em detrimento de outras, para facilitar a compreensão de uma alternativa ponderada aos extremos do ativismo solipsista e da autorrestrição judicial.

Vale destacar que tanto o termo "ativismo" puro e simples, quanto a expressão "autocontenção", são nomenclaturas subjetivas para descrever comportamentos judiciais que, na prática, fogem do modelo fidedigno de "juiz ativista" / "juiz deferente” e envolvem subjetividades, que podem fazer com o adjetivo trivial utilizado pelo crítico não corresponda diretamente à integralidade da postura judicial. Um juiz pode ser ativista ao adotar uma postura deferente às escolhas políticas, por questões óbvias e por questões que dificilmente poderiam ser listadas por um observador externo. Desse modo, ativismo e a autocontenção judicial, em determinadas matérias, podem refletir uma manobra política do magistrado, uma ação de proteção institucional, uma preferência pessoal ou, em contrapartida, podem significar que, de fato, aquele juiz acredita que não deve interferir naquele assunto específico, seja por falta de expertise e/ou legitimidade democrática.

Essa linha de raciocínio é desenvolvida, no Brasil, pela jurista Flávia Santiago ${ }^{5}$, que mescla elementos políticos e jurídicos para testar a hipótese - confirmada ao final do livro de que, ativismo e autocontenção, ao fim e ao cabo, são expressões contingentes. A autora destrincha o assunto em outras oportunidades e aprofunda a ideia de que, de fato, existem mais variáveis que moldam o jogo democrático que aquelas que podem ser vistas a olho nu ou percebidas em estudos superficiais.

\footnotetext{
3 LIMA, Flavia Danielle Santiago; FRANÇA, Eduarda Peixoto da Cunha. Ativismo dialógico x bloqueios institucionais: limites e possibilidades do controle jurisdicional de políticas públicas a partir da Sentencia T025/04 da Corte Colombiana. Argumenta Journal Law, n. 31, jul./dez, 2019, p. 230.

4 ALBUQUERQUE, Felipe. SERAFIM, Matheus. A importância da participação pública nos processos estruturais: contribuições da teoria normativa de Susan Sturm. Revista Estudos Institucionais, v. 6, n. 2, mai./ago. 2020, p. 648.

5 LIMA, Flávia Danielle Santiago Lima. Jurisdição constitucional e política: ativismo e autocontenção no STF. Curitiba: Juruá, 2014.
} 
Nesse mesmo sentido, Carlos Alexandre de Azevêdo Campos ${ }^{6}$ apresenta algumas classificações de ativismo judicial no Supremo Tribunal Federal, no propósito de demonstrar que o “(...) ativismo judicial não pode ser considerado aprioristicamente ilegítimo, pois isso depende dos diferentes fatores envolvidos e da dimensão decisória manifestada", de forma que somente a dimensão dita "antidialógica", para o autor, seria ilegítima. O fato é que podem existir tantas concepções e ideias acerca do ativismo e de autocontenção quantos forem os autores que escreverem sobre a temática, não parecendo haver empecilhos para trabalhar, no presente estudo, uma nomenclatura de um protótipo ideal de comportamento judicial quando do enfrentamento de litígios estruturais (e que, na prática, já existe).

Ultrapassada essa preliminar, a primeira vantagem do chamado "ativismo dialógico" é a não incorrência da atuação judicial nas clássicas objeções à função contramajoritária: a falta de legitimidade dos magistrados de interferirem em matérias políticas e a ausência de expertise destes atores em tratar quesitos que não são naturais à sua função típica. Ele impede, assim, que o Poder Judiciário tome medidas autorreferenciadas e que pouco ou nada influenciarão na realidade prática e, ao mesmo tempo, evita que o Poder Judiciário adote uma postura tão deferente que esvazie o conteúdo normativo dos DESC, deixando-os dependentes da discricionariedade das instâncias majoritárias.

O ativismo dialógico, assim, implica que: 1) o Poder Judiciário, diante da inafastabilidade da jurisdição e da consequente responsabilidade de atuar para promover a efetividade dos dispositivos constitucionais - e, sobretudo, dos direitos fundamentais, vai agir e não se isentar do mister que lhe foi constitucionalmente atribuído; e 2) vai fazer isso sem interferir, injustificadamente, em matérias que fogem de sua expertise ou substituir decisões políticas e técnicas tomadas pelas instâncias majoritárias.

Assim, a postura adotada no ativismo dialógico deve ser a de definir as metas e os caminhos para a implementação de políticas públicas e acompanhar e monitorar o progresso do cumprimento de sentença sem tomar para si as decisões mais importantes, que devem ser atribuídas às agências governamentais. $\mathrm{O}$ foco desse tipo de ativismo é o de fomentar $\mathrm{o}$ diálogo institucional para que os entes estatais responsáveis atuem conforme as suas atribuições típicas e dentro dos limites orçamentários disponíveis, buscando construir

\footnotetext{
6 CAMPOS, Carlos Alexandre de Azevedo. Dimensões do Ativismo Judicial do STF. Rio de Janeiro:
} Forense, 2014, p. 15. 
soluções coparticipativas que permitam a atuação dos envolvidos dentro de suas esferas tradicionais de competência.

Decisões dialógicas apontam o erro e chamam os responsáveis para iniciar um debate, regido pelo Poder Judiciário, a fim de que se construa um plano capaz de reverter ou mitigar a situação vigente que dá ensejo à violação de direitos. Para garantir que esse plano será cumprido, o Poder Judiciário mantém a supervisão e o monitoramento da execução da sentença, podendo ajustar pontos que não são mais condizentes com a realidade. Importante frisar que até a revisão do plano inicial deve ser feita de modo a permitir a participação dos interessados e a influência dos pontos de vista das instituições violadoras, viabilizando uma maior reflexão e compreensão do problema enfrentado e evitando que o Poder Judiciário imponha medidas pouco eficientes ou deficitárias em detrimento de sua não correspondência com a realidade. Decisões judiciais rígidas e unilaterais podem comprometer por completo a eficiência de todo o processo estrutural. O diálogo, em contrapartida, abre margem para um espaço no qual as possibilidades são apresentadas e as medidas são tomadas, mas, quando necessário, são constantemente rediscutidas.

É certo que a adoção dessa postura dialógica nem sempre garante o sucesso completo ou parcial da demanda, mas é uma postura que demonstra um maior comprometimento com os setores políticos e um maior cuidado com a solução do processo estrutural. A implementação dos direitos constitucionais, todavia, depende, em grande parte, da atmosfera ideológica, das restrições institucionais específicas e das metacondições econômicas e sociais nas quais eles estejam inseridos ${ }^{7}$.

Apresentar o ativismo dialógico enquanto possível postura adequada de atitude judicial para o tratamento de questões estruturais não é uma panaceia ou uma solução milagrosa para problemas demasiadamente complexos; é, tão somente, uma maneira de tentar conciliar uma realidade posta - o controle jurisdicional de políticas públicas - com o "dever ser" - não compete à função jurisdicional a tarefa de implementação de programas de ação governamental -, de modo a encontrar uma terceira via para questões que só são vistas a partir de vieses binários (autocontenção ou ativismo solipsista). Nesse sentido, serão apresentadas duas teorias que, se combinadas, podem retratar posturas interessantes ao

\footnotetext{
7 HIRSCHL, Ran. Towards juristocracy: The origins and consequences of the constitutionalism. Cambridge: Harvard University Press, 2004, p.361.
} 
enfrentamento de questões estruturais pelo Poder Judiciário no cenário brasileiro.

\subsection{Teoria desenvolvida por Susan Sturm para sentenças estruturais dialógicas}

A fim de estabelecer diretrizes normativas para a utilização de uma sentença estrutural dialógica, Susan Sturm desenvolveu uma teoria normativa que envolve os seguintes pontos: participação, respeito à teoria da separação dos poderes, imparcialidade, fundamentação adequada das decisões e remediação ${ }^{8}$.

A participação diz respeito ao fato de que os grupos afetados pelo litígio estrutural devem ter a oportunidade de influenciar de forma que seus pontos de vista interfiram diretamente nas medidas proferidas para a implementação da sentença. Os propósitos da participação, para a autora, são: assegurar a dignidade das partes atingidas pelo problema estrutural - uma vez que serão consideradas "parceiras" na construção das soluções negociadas -, e engajar o público afetado na efetivação do remédio estrutural ${ }^{9}$.

Para evitar desequilíbrios de participação nos processos de negociação acerca das medidas estruturais que serão prolatadas pelo juiz (que podem inviabilizar, em maior ou menor grau, a participação efetiva de grupos vulneráveis no processo deliberativo), a autora sugere que segmentos sociais marginalizados sejam auxiliados por instituições tecnicamente capacitadas, com expertise na defesa dos direitos fundamentais que estão sendo violados no litígio. Sturm aponta, ademais, a imprescindibilidade de que os referidos representantes atuem com accountability, de maneira que não só prestem satisfação de suas ações à comunidade representada, como, também, que defendam da forma mais fidedigna possível os interesses dos representados ${ }^{10}$.

Outro quesito importante é que o Poder Judiciário adote formas de intervenção capazes de fomentar a cooperação e o consenso, fugindo da lógica adversarial, tipicamente incorporada nos processos bipolares ${ }^{11}$. O referido poder também exerce um papel importante

\footnotetext{
8 STURM, Susan P. A normative theory of public law remedies. Georgetown Law Journal, v. 79, 1991, p. 1392.

${ }^{9}$ STURM, Susan P. A normative theory of public law remedies. Georgetown Law Journal, v. 79, 1991, p. 1392.

10 STURM, Susan P. A normative theory of public law remedies. Georgetown Law Journal, v. 79, 1991, p. 1410.

11 STURM, Susan P. A normative theory of public law remedies. Georgetown Law Journal, v. 79, 1991, p.
} 
para a equalização da discussão, assegurando um processo deliberativo justo e equitativo, não permitindo a simples imposição das vontades de uma parte sobre a outra ${ }^{12}$.

No que concerne ao respeito à separação dos poderes, Sturm ${ }^{13}$ argumenta que as decisões judiciais que envolvem litígios estruturais devem ter atenção às competências típicas das instituições governamentais envolvidas no processo. Se o Poder Judiciário respeitar a integridade dos órgãos públicos, as críticas envolvendo a legitimidade democrática de sentenças estruturais poderiam ser mitigadas, argumenta a autora ${ }^{14}$. A questão, dessa forma, volta-se para "como" o Poder Judiciário deve construir as decisões estruturais e não para "se" este Poder deveria ou não tomar essas decisões. Não é que o “dever ser" não seja importante, mas ele pouco contribui com a mudança do status quo vigente. Pensar em como melhorar a realidade, a partir do que ela é e não daquilo que ela deveria ser, é a chave fundamental para mudanças promissoras.

O terceiro fator apontado por Sturm ${ }^{15}$ é que os juízes devem ter cautela ao prolatarem sentenças estruturais, buscando sempre a imparcialidade e a objetividade na formulação da decisão. Por mais que a imparcialidade seja uma garantia fundamental de todo e qualquer processo judicial, o estudo dos chamados "vieses cognitivos", frequentemente trabalhados na psicologia e economia comportamental ${ }^{16}$, chama atenção para o perigo das subjetividades

1410.

12 SCOTT, Joanne; STURM, Susan. Courts as catalysts: re-thinking the judicial role in new governance.

Columbia Journal of European Law, v. 13, p. 565-594, 2006, p. 565-566.

13 STURM, Susan P. A normative theory of public law remedies. Georgetown Law Journal, v. 79, 1991, p. 1410.

14 STURM, Susan P. A normative theory of public law remedies. Georgetown Law Journal, v. 79, 1991, p. 1405.

15 STURM, Susan P. A normative theory of public law remedies. Georgetown Law Journal, v. 79, 1991, p. 1397-1398.

16 Nesse sentido: "Afortunadamente, nos últimos anos, a literatura jurídica brasileira tem começado a se questionar sobre a existência e os efeitos de vieses cognitivos na tomada de decisão juridicamente relevante. Mais recentemente, trabalhos teóricos e empíricos têm utilizado como ponto de partida as referências da literatura em Julgamento e Tomada de Decisão, Ciências Comportamentais e Economia Comportamental para entender esse fenômeno, renovando o repertório de análises e formulações do problema da decisão no Direito.Trata-se de um movimento que já vinha de alguns anos na literatura estrangeira, amparado por dezenas de experimentos e estudos empíricos que constataram aquilo que muitos já intuíam: nas decisões moralmente carregadas e/ou juridicamente relevantes, as pessoas são influenciadas por fatores pessoais, políticoideológicos (...) Embora a comunidade jurídica tenha sido lenta em reconhecer a existência desses vieses cognitivos nas atividades decisórias, a sua importância não pode ser mais ignorada. As consequências das limitações da racionalidade humana na prática forense são reais e podem resultar em injustiças concretas (...)". HORTA, Ricardo Lins. Por que existem vieses cognitivos na Tomada de Decisão Judicial? A contribuição da Psicologia e das Neurociências para o debate jurídico. Revista Brasileira de Políticas Públicas, v. 9, n. 3, 2019, p. 85-86. 
na hora da prolação de sentenças.

Vitorelli ao tratar da ideia de "vieses cognitivos" no discernimento do juiz envolvido em um processo estrutural ${ }^{17}$, aponta que existem diversas pré-compreensões capazes de condicionar a interpretação do juiz, o que facilita a sua adesão, ainda que inconsciente, aos interesses de uma das partes do litígio. Em decorrência da complexidade dos processos estruturais, que lidam com uma diversidade de interesses, a interferência dessas heurísticas pode ser prejudicial ${ }^{18}$. Sendo assim, Vitorelli alerta que o juiz precisa estar ciente desses riscos, bem como de técnicas que sejam propícias a auxiliar na diminuição da influência dos diferentes vieses ${ }^{19}$.

O quarto ponto apresentado por Sturm é a necessidade de que a decisão seja bem fundamentada, de forma a justificar as medidas estruturais que foram prolatadas. Os magistrados devem listar os motivos que os influenciaram na hora da tomada de decisão e essas razões devem ter bases empíricas e levar em consideração circunstâncias do caso concreto, bem como disposições normativas e precedentes judiciais, capazes de demonstrar a adequação jurídica da escolha ${ }^{20}$. Essas observações também são capazes de auxiliar o Poder Judiciário na construção de melhores decisões estruturais futuras, que tratem de casos similares $^{21}$.

Por último, a autora sustenta a remediação, que significa que a sentença estrutural deve estar apta a propiciar a proteção dos direitos fundamentais violados. Em suma, é

17 VITORELLI, Edilson. Litígios Estruturais: decisão e implementação de mudanças socialmente relevantes pela via processual. In: ARENHART, Sérgio Cruz; JOBIM, Marco Félix (Org.). Processos Estruturais. Salvador: Juspodivm, 2017. p. 384-385.

18 Importante destacar que "Levar a sério esses vieses não significa buscar e acatar necessariamente uma concepção de índole realista (realismo jurídico que, de modo recorrente, aposta na força decisória embasada no discurso positivista da autoridade do decisor para criar o direito), que aqui se rechaça, mas, mediante sua percepção, gerar constrangimentos racionais (embasados numa leitura forte dos princípios processuais constitucionais) para que o uso da linguagem, pelo decisor e partes, se estruture de modo que se desincumbam de seus ônus argumentativos e promova-se a formação dialógica das decisões, impedindo-se escolhas solitárias e exercícios discricionários do poder.", NUNES, Dierle. Colegialidade corretiva, precedentes e vieses cognitivos: algumas questões do CPC-2015. Revista do TRF3-Ano XXVII-n, 2016, p. 72.

19 VITORELLI, Edilson. Litígios Estruturais: decisão e implementação de mudanças socialmente relevantes pela via processual. In: ARENHART, Sérgio Cruz; JOBIM, Marco Félix (Org.). Processos Estruturais. Salvador: Juspodivm, 2017. p. 390-391.

20 STURM, Susan P. A normative theory of public law remedies. Georgetown Law Journal, v. 79, 1991, p. 1411.

21 STURM, Susan P. A normative theory of public law remedies. Georgetown Law Journal, v. 79, 1991, p. 1411. 
importante que a decisão aponte, de forma explícita, quais são os direitos fundamentais violados no caso em questão, quais as obrigações das partes e porque o remédio escolhido é o mais preciso diante dos interesses imbricados e, muitas vezes, conflitantes ${ }^{22}$. A autora também ressalta a importância de que os juízes fixem critérios para avaliar as medidas que serão implementadas e que o façam em diálogo com as partes.

\subsection{A postura consequencialista, estratégica e mediadora do magistrado}

A decisão judicial sobre litígios estruturais de interesse público amplia o ônus de argumentação do julgador, que deve, segundo Susana Henriques da $\operatorname{Costa}^{23}$, agir de maneira consequencialista, estratégica e mediadora, além de utilizar uma estrutura argumentativa racional, clara e voltada não somente ao convencimento das partes ou das instâncias superiores, mas, também, à própria legitimação pública do teor do julgado.

A postura consequencialista pode ser entendida como aquela na qual o magistrado pondera sobre os efeitos materiais de sua decisão na sociedade. O juiz que decide, por exemplo, acerca de políticas públicas, não pode ser alheio aos impactos, complexidades e dificuldades da execução de sua decisão. Existem limites fáticos (como, por exemplo, os de cunho orçamentário e operacional) que podem vir a impedir a eficácia do mandamento contido na sentença ou que dificultem o cumprimento de ordens judiciais em prazos exíguos, e esses quesitos precisam ser levados em consideração pelo magistrado, de maneira a equilibrar os valores em questão e buscar um equacionamento mais adequado do conflito ${ }^{24}$.

Ainda acerca do consequencialismo, importante destacar o artigo 20 da Lei de Introdução às Normas do Direito Brasileiro (LINDB), que dispõe que "Nas esferas administrativa, controladora e judicial, não se decidirá com base em valores jurídicos

\footnotetext{
22 STURM, Susan P. A normative theory of public law remedies. Georgetown Law Journal, v. 79, 1991, p. 1399.

${ }^{23}$ COSTA, Susana Henriques da. A Imediata Judicialização dos Direitos Fundamentais Sociais e o Mínimo Existencial: Relação Direito e Processo. In: GRINOVER, Ada Pellegrini; WATANABE, Kazuo e COSTA, Susana Henriques da (org.) O processo para solução de conflitos de interesse público, São Paulo: Juspodivm, 2017, p. 415.

${ }^{24}$ COSTA, Susana Henriques da. A Imediata Judicialização dos Direitos Fundamentais Sociais e o Mínimo Existencial: Relação Direito e Processo. In: GRINOVER, Ada Pellegrini; WATANABE, Kazuo e COSTA, Susana Henriques da (org.) O processo para solução de conflitos de interesse público, São Paulo: Juspodivm, 2017, p. 415.
} 
abstratos sem que sejam consideradas as consequências práticas da decisão". Assim, a LINDB fez com que a antecipação das consequências futuras se transformasse em causa para a adoção ou não de um ato ${ }^{25}$. Desse raciocínio, extrai-se, portanto, que a referida lei adotou um parâmetro para a concretização dos valores abstratos contidos no ordenamento jurídico: as consequências práticas da decisão ${ }^{26}$. Logo, ao se deparar com direitos e princípios abstratos, o julgador deve projetar as consequências de sua decisão para o futuro, objetivando a produção de melhores resultados sociais.

Uma outra questão a ser observada é a postura estratégica que pode ser adotada pelo juiz. Isso porque decisões acerca de litígios estruturais de interesse público estão quase sempre relacionadas à implementação ou correção de uma política pública, de forma que até que esta seja concretizada ou ajustada, haverá muito a se decidir. Para que se chegue ao escopo objetivado, o juiz deve traçar uma estratégia, um plano de atuação, de forma a incluir a participação das partes envolvidas no conflito. Exigir que o executado simplesmente cumpra o teor da decisão em determinado prazo (postura demasiadamente formalista), sem acompanhar esse cumprimento e os percalços que podem ser encontrados no caminho, torna menores as chances de êxito da execução, que precisa ser pensada a partir de medidas específicas, porém flexíveis. É preciso que exista um equilíbrio entre a especificidade e o generalismo. O plano não pode ser genérico a ponto de que as diretrizes gerais para o seu funcionamento não consigam ser estabelecidas e nem tão específico que não admita mudanças a depender das circunstâncias em questão. $O$ juiz deve acompanhar as contingências processuais, bem como o cumprimento dos planos e dos prazos, atuando de forma estratégica.

Por fim, o juiz deve atuar enquanto mediador não somente das partes como, também, das instituições envolvidas. Afinal, a definição e a implementação de políticas públicas dependem, necessariamente, da atuação de mais de um dos Poderes do Estado de forma concatenada e na busca de um mesmo objetivo. O Judiciário, dessa forma, quando funciona enquanto locus de debate e resolução de litígios estruturais de interesse público, atua como mediador dessa transformação, possibilitando uma interlocução entre as instituições envolvidas, o Ministério Público e a sociedade civil.

\footnotetext{
25 VITORELLI, Edilson. Processo Civil Estrutural: Teoria e Prática. Salvador: Juspodium, p. 103. 26 VITORELLI, Edilson. Processo Civil Estrutural: Teoria e Prática. Salvador: Juspodium, p. 104.
} 


\section{Limites ao diálogo na esfera do controle concentrado de constitucionalidade: uma análise da ADPF 347}

O Estado de Coisas Inconstitucional (ECI) é um instituto criado pela Corte Constitucional colombiana, que é considerada por muitos como uma das cortes mais "ativistas" - no sentido de garantir direitos humanos - no mundo ${ }^{27}$. Sua decretação depende de alguns requisitos, dentre os quais destacam-se: a) a violação massiva e generalizada de vários direitos constitucionais que afeta um número significativo de pessoas; b) a omissão prolongada das autoridades no cumprimento de suas obrigações para garantir os direitos; c) a existência de um problema social cuja solução comprometa a intervenção de várias entidades, requer a adoção de um conjunto complexo e coordenado de ações, e demanda um nível de recursos que exija um esforço orçamentário adicional importante; d) potencialidade de congestionamento da justiça, se todos os que tiverem os seus direitos violados acorrerem individualmente ao Poder Judiciário ${ }^{28}$. O instituto permite, ainda, que juízes constitucionais imponham aos Poderes Públicos a tomada de ações urgentes e necessárias ao afastamento das violações massivas de direitos fundamentais, bem como que supervisionem a sua implementação.

Em setembro de 2015, o Supremo Tribunal Federal (STF) reconheceu, em sede de liminar, um Estado de Coisas Inconstitucional (ECI) no sistema carcerário brasileiro, ocasionado por violações generalizadas de direitos fundamentais e reiterada inércia estatal, implicando a determinação de medidas estruturais flexíveis a serem manejadas e monitoradas pela corte, com o auxílio dos demais poderes, órgãos e pessoas afetadas.

Em apertada síntese, o autor (partido PSOL) afirmou que a superlotação do sistema carcerário brasileiro, bem como as condições degradantes deste, configurariam um cenário fático completamente incompatível com a Constituição brasileira. Isso porque os cárceres do país ofendem uma pluralidade de direitos fundamentais, tais quais "a dignidade da pessoa

27 CAMPOS, Carlos Alexandre de Azevedo. Dimensões do Ativismo Judicial do STF. Rio de Janeiro: Forense, 2014, p. 38.

28 COLOMBIA. Corte Constitucional Colombiana. Sentença T-25/04. Abel Antonio Jaramillo e outros e Red de Solidaridad Social e outros. Relator: Magistrado Manuel José Cepeda Espinosa. Bogotá, COLÔMBIA, 24 de janeiro de 2004. Disponível em: https:/www.corteconstitucional.gov.co/relatoria/2004/t-025-04.htm. Acesso em: 14 set. 2020, p. 4. 
humana, a vedação de tortura e de tratamento desumano, o direito de acesso à Justiça e os direitos sociais à saúde, educação, trabalho e segurança dos presos”. Ademais, declararam que o quadro era proveniente de uma "multiplicidade de atos comissivos e omissivos "dos Poderes Públicos da União, dos Estados e do Distrito Federal, incluídos os de natureza normativa, administrativa e judicial" 29 .

Em suas alegações, o partido ressaltou que os órgãos administrativos menosprezariam os preceitos constitucionais e legais ao não viabilizarem a criação de um número de vagas prisionais compatíveis com o tamanho da população carcerária, de forma a proporcionar condições dignas de encarceramento aos presos e consequente proteção à sua segurança física, saúde, alimentação, educação, trabalho, assistência social e acesso à jurisdição ${ }^{30}$.

Ainda nesse sentido, vale o destaque de um ponto importante: além da generalizada violação aos direitos dos presos, foi registrado o perigo que as mazelas do sistema penitenciário provocam na sociedade como um todo, pois as condições degradantes nas quais eram (e ainda são) cumpridas as penas privativas de liberdade e a mistura entre os presos com graus diferentes de periculosidade tornariam o trabalho de ressocialização dos detentos uma quimera, propiciando reincidências constantes. Assim, a prisão tornar-se-ia uma verdadeira "escola do crime" e a forma como funciona o sistema estaria somente agravando esta situação ${ }^{31}$. Afinal, ao contrário do que se imagina, o encarceramento em massa não geraria a segurança prometida, mas, tão somente, agravaria os índices de criminalidade e violência social em detrimento de toda a população.

No mérito, o autor da Arguição de Descumprimento de Preceito Fundamental (ADPF) requereu, entre outros pedidos:

a) que fossem determinados ao Governo Federal a elaboração e o

29 BRASIL. Supremo Tribunal Federal. Medida Cautelar na ADPF 347. ADPF $n^{\circ}$ 347. PARTIDO SOCIALISMO E LIBERDADE. Relator: Ministro Marco Aurélio. 09 de setembro de 2015. Disponível em: http://redir.stf.jus.br/paginadorpub/paginador.jsp?docTP=TP\&docID=10300665. Acesso em: 14 set 2020, p. 8 . 30 BRASIL. Supremo Tribunal Federal. Medida Cautelar na ADPF 347. ADPF $n^{\circ}$ 347. PARTIDO SOCIALISMO E LIBERDADE. Relator: Ministro Marco Aurélio. 09 de setembro de 2015. Disponível em: http://redir.stf.jus.br/paginadorpub/paginador.jsp?docTP=TP\&docID=10300665. Acesso em: 14 set 2020, p. 89 .

31 BRASIL. Supremo Tribunal Federal. Medida Cautelar na ADPF 347. ADPF $\mathrm{n}^{\circ}$ 347. PARTIDO SOCIALISMO E LIBERDADE. Relator: Ministro Marco Aurélio. 09 de setembro de 2015. Disponível em: http://redir.stf.jus.br/paginadorpub/paginador.jsp?docTP=TP\&docID=10300665. Acesso em: 14 set 2020, p. 12. 
Revista Eletrônica de Direito Processual - REDP.

Rio de Janeiro. Ano 16. Volume 23. Número 1. Janeiro a Abril de 2022

Periódico Quadrimestral da Pós-Graduação Stricto Sensu em Direito Processual da UERJ

Patrono: José Carlos Barbosa Moreira (in mem.). ISSN 1982-7636. pp. 389-415

www.redp.uerj.br

encaminhamento ao Supremo, no prazo de três meses, de um plano nacional visando à superação, dentro de três anos, do quadro dramático do sistema penitenciário brasileiro; b) que o aludido plano contivesse propostas e metas; c) que o plano previsse os recursos necessários à implementação das propostas e o cronograma para a efetivação das medidas; d) que o plano fosse submetido à análise do Conselho Nacional de Justiça (CNJ), da Procuradoria-Geral da República (PGR), da Defensoria-Geral da União, do Conselho Federal da Ordem dos Advogados do Brasil (CFOAB), do Conselho Nacional do Ministério Público (CNMP) e de outros órgãos e instituições que desejassem se manifestar e da sociedade civil; e) que o Tribunal deliberasse sobre o plano, para homologá-lo ou impor providências alternativas ou complementares; f) uma vez homologado o plano, fosse determinado aos governos dos Estados e do Distrito Federal que formulassem e apresentassem ao Supremo, em três meses, planos próprios em harmonia com o nacional, contendo metas e propostas específicas para a superação do ECI; g) que o Tribunal deliberasse sobre cada plano estadual e distrital, para homologálos ou impor providências alternativas ou complementares; e h) que o Supremo monitorasse a implementação dos planos nacional, estaduais e distrital, com o auxílio do Departamento de Monitoramento e Fiscalização do Sistema Carcerário (DMF) e do Sistema de Execução de Medidas Socioeducativas do $\mathrm{CNJ}$, em processo público e transparente, aberto à participação colaborativa da sociedade civil ${ }^{32}$.

Após descrever a deplorável situação da população carcerária no Brasil, o relator, Ministro Marco Aurélio, confirmou que dela decorrem inúmeras violações de direitos fundamentais, bem como de preceitos básicos presentes na Lei de Execução Penal (Lei ${ }^{\circ}$ 7.210, de 1984) ${ }^{33}$. A responsabilidade por essa situação, desse modo, recairia sobre os três Poderes da República: Executivo, Legislativo e Judiciário, tendo em vista sua falta de coordenação institucional. A intervenção do Supremo Tribunal Federal, portanto, seria justificável na medida em que se fizesse necessária para superar a inércia ou omissão proposital das instâncias majoritárias.

Afinal, diante de um cenário de bloqueios políticos, pontos cegos políticos e inércia proposital das instâncias majoritárias (em virtude do tema ser desinteressante e custoso aos membros do Poder Legislativo e Executivo), cumpriria ao STF “catalisar ações e políticas

\footnotetext{
32 MAGALHÃES, Breno Baía. A incrível doutrina de um caso só: análise do estado de coisas inconstitucional na ADPF 347. Revista Eletrônica do Curso de Direito da UFSM, Santa Maria, RS, v. 14, n. 3, e32760, set./dez. 2019. ISSN 1981-3694. DOI: http://dx.doi.org/10.5902/1981369432760. Disponível em: https://periodicos.ufsm.br/revistadireito/article/view/32760. Acesso em: 14 set. 2020, p. 13.

33 BRASIL. Supremo Tribunal Federal. Medida Cautelar na ADPF 347. ADPF $n^{0} 347$. PARTIDO SOCIALISMO E LIBERDADE. Relator: Ministro Marco Aurélio. 09 de setembro de 2015. Disponível em: http://redir.stf.jus.br/paginadorpub/paginador.jsp?docTP=TP\&docID=10300665. Acesso em: 14 set. 2020, p. 12 .
} 
Revista Eletrônica de Direito Processual - REDP.

Rio de Janeiro. Ano 16. Volume 23. Número 1. Janeiro a Abril de 2022

Periódico Quadrimestral da Pós-Graduação Stricto Sensu em Direito Processual da UERJ

Patrono: José Carlos Barbosa Moreira (in mem.). ISSN 1982-7636. pp. 389-415

www.redp.uerj.br

públicas, coordenar a atuação dos órgãos do Estado na adoção dessas medidas e monitorar a eficiência das soluções" ${ }^{34}$ a fim de verificar o (in)sucesso dos meios escolhidos, emitindo ordens flexíveis, que proporcionariam margens de criação legislativa e de execução a serem esquematizadas e implementadas pelos demais poderes ${ }^{35}$.

Dessa forma, o Tribunal atuaria enquanto um coordenador institucional, capaz de produzir um efeito desbloqueador, sem interferir, entretanto, na elaboração de políticas públicas ${ }^{36}$. Os argumentos do relator foram repetidos, com pouca variação, pelos Ministros Fachin, Barroso, Zavascki, Weber, Fux, Cármen Lúcia, Celso de Mello e Lewandowski.

Passados quatro anos de sua declaração, não obstante os muitos trabalhos produzidos acerca da temática e os debates que giravam em torno da denúncia (acertada) do estado de calamidade em que se encontrava o sistema carcerário do país, pouco ou nada mudou na vida dos detentos ${ }^{37}$. O presente artigo, dessa forma, tentará identificar se os argumentos utilizados pelo ministro relator, em sede de liminar, buscavam engajar o Supremo Tribunal Federal em um diálogo institucional com as instâncias políticas, partindo da análise de três pontos trazidos em seu voto, quais sejam: i) a falência total das políticas públicas existentes para a questão prisional; ii) a impopularidade e sub-representação dos presos em detrimento de perderem os seus direitos políticos e da antipatia da opinião pública, respectivamente; iii) a necessidade de um diálogo cooperativo entre os Poderes (e não da imposição judicial de medidas rígidas e inflexíveis), tendo em vista a responsabilidade de todas as funções estatais no que concerne ao sistema carcerário do país.

\footnotetext{
34 MAGALHÃES, Breno Baía. A incrível doutrina de um caso só: análise do estado de coisas inconstitucional na ADPF 347. Revista Eletrônica do Curso de Direito da UFSM, Santa Maria, RS, v. 14, n. 3, e32760, set./dez. 2019. ISSN 1981-3694. DOI: http://dx.doi.org/10.5902/1981369432760. Disponível em: https://periodicos.ufsm.br/revistadireito/article/view/32760 Acesso em: 14 set. 2020, p. 9.

35 MAGALHÃES, Breno Baía. A incrível doutrina de um caso só: análise do estado de coisas inconstitucional na ADPF 347. Revista Eletrônica do Curso de Direito da UFSM, Santa Maria, RS, v. 14, n. 3, e32760, set./dez. 2019. ISSN 1981-3694. DOI: http://dx.doi.org/10.5902/1981369432760. Disponível em: https://periodicos.ufsm.br/revistadireito/article/view/32760 Acesso em: 14 set. 2020, p. 9.

36 MAGALHÃES, Breno Baía. A incrível doutrina de um caso só: análise do estado de coisas inconstitucional na ADPF 347. Revista Eletrônica do Curso de Direito da UFSM, Santa Maria, RS, v. 14, n. 3, e32760, set./dez. 2019. ISSN 1981-3694. DOI: http://dx.doi.org/10.5902/1981369432760. Disponível em: https://periodicos.ufsm.br/revistadireito/article/view/32760 Acesso em: 14 set. 2020, p. 9.

37 MAGALHÃES, Breno Baía. A incrível doutrina de um caso só: análise do estado de coisas inconstitucional na ADPF 347. Revista Eletrônica do Curso de Direito da UFSM, Santa Maria, RS, v. 14, n. 3, e32760, set./dez. 2019. ISSN 1981-3694. DOI: http://dx.doi.org/10.5902/1981369432760. Disponível em: https://periodicos.ufsm.br/revistadireito/article/view/32760 Acesso em: 14 set. 2020, p. 9.
} 


\subsection{A falência total das políticas públicas prisionais em detrimento do hiperencarceramento no país: complexidade, experimentalismo e cultura punitivista como empecilhos}

A superlotação do sistema carcerário brasileiro não é uma questão nova e já estava na pauta do Supremo antes da ADPF 347. A maior parte dos detentos, conforme o Ministro Marco Aurélio, está sujeita a condições de superlotação dos presídios, torturas, homicídios, violência sexual, celas sujas e insalubres, proliferação de doenças infectocontagiosas, falta de produtos higiênicos básicos, falta de água potável, falta de acesso à assistência judiciária, à educação, à saúde e ao trabalho. Além disso, os cárceres brasileiros encontram-se sob o domínio de organizações criminosas e o controle quanto aos meios de penas são insatisfatórios e obscuros ${ }^{38}$.

O ministro expôs, ainda nessa oportunidade, que a superlotação carcerária poderia ser a origem de todos os males, a fonte que dá ensejo a todos os outros problemas, e que o modo de funcionamento do cárcere brasileiro não serve à ressocialização dos presos, além de aumentar a criminalidade e viabilizar que os reincidentes passem a cometer crimes ainda mais graves ${ }^{39}$. Ainda nesse sentido, vale o destaque feito pelo relator de que o Judiciário que seria responsável, inclusive, pela "cultura do encarceramento" em virtude do número excessivo de prisões provisórias - e a Defensoria Pública contariam com um número insuficiente de Varas de Execuções Penais e este fato implicaria no encarceramento acima do determinado judicialmente, o que agravaria a violação aos direitos fundamentais processuais dos presos, que, muitas vezes, sequer possuem informações sobre os processos criminais que lhes dizem respeito ${ }^{40}$.

Apesar da sumarização dos argumentos acerca da insuficiência das políticas públicas

38 BRASIL. Supremo Tribunal Federal. Medida Cautelar na ADPF 347. ADPF no 347. PARTIDO SOCIALISMO E LIBERDADE. Relator: Ministro Marco Aurélio. 09 de setembro de 2015. Disponível em: http://redir.stf.jus.br/paginadorpub/paginador.jsp?docTP=TP\&docID=10300665. Acesso em: 14 set 2020, p. 5 . 39 BRASIL. Supremo Tribunal Federal. Medida Cautelar na ADPF 347. ADPF $n^{\circ}$ 347. PARTIDO SOCIALISMO E LIBERDADE. Relator: Ministro Marco Aurélio. 09 de setembro de 2015. Disponível em: http://redir.stf.jus.br/paginadorpub/paginador.jsp?docTP=TP\&docID=10300665. Acesso em: 14 set 2020, p. 5. 40 BRASIL. Supremo Tribunal Federal. Medida Cautelar na ADPF 347. ADPF no 347. PARTIDO SOCIALISMO E LIBERDADE. Relator: Ministro Marco Aurélio. 09 de setembro de 2015. Disponível em: http://redir.stf.jus.br/paginadorpub/paginador.jsp?docTP=TP\&docID=10300665. Acesso em: 14 set 2020, p. 10. 
do sistema carcerário, não se faz difícil compreender que um dos argumentos centrais utilizados pelo PSOL é a necessidade de criação ou ajustes dos programas estatais já existentes. Existem, dessa forma, três pontos que precisam ser enfrentados: o experimentalismo e a complexidade, próprios das demandas estruturais, que exigem medidas flexíveis e que darão ensejo a resultados imprevisíveis x a cultura punitivista existente no país - que figura enquanto uma das causas principais do hiperencarceramento -; a impopularidade e sub-representação dos presos x resultados de longo prazo; e a necessidade de diálogo entre os Poderes em detrimento do ECI prisional ser decorrente da falta de coordenação entre eles.

Para enfrentar as questões do parágrafo anterior é necessário pensar "a longo prazo", prática custosa não só à população brasileira, como, também, às instituições do país (notadamente imediatistas). O fato é que, sempre que uma determinada demanda envolver questões estruturais de interesse público, as medidas tomadas pelos Poderes e demais atores envolvidos hão de ser experimentais e complexas. Se não houver espaço para o ciclo de “tentativa $\rightarrow$ erro; tentativa $\rightarrow$ acerto; tentativa $\rightarrow$ descoberta de novos caminhos", nunca se poderá atingir a solução desejada. Isso porque matérias referentes a políticas públicas, por sua natureza, dependem de variáveis imprevisíveis e contingenciais, que só poderão ser identificadas na prática e no momento de sua implementação ou ajuste.

Importante salientar, ainda nesse sentido, que processos que enfrentam os litígios estruturais devem ter um foco prospectivo (ou seja, busca-se uma solução futura, capaz de dar fim à continuidade do problema, e não uma reparação por um ilícito ocorrido, como ocorre no processo bipolar), e, portanto, deve-se levar em consideração a mutabilidade da situação e da tutela necessária, de forma que seja possível pensar na adaptabilidade do procedimento a depender da contingencialidade das circunstâncias.

Outro pronto importante é que, ainda que houvesse coordenação institucional no ajuste e/ou implementação de políticas públicas no sistema carcerário, o Brasil sustenta, ainda, uma cultura demasiadamente punitivista. Há uma percepção social, no país, de que a prisão é a saída para o "castigo da violação de uma transgressão criminal, tendo em vista a formação de um cidadão que não mereça estar na cadeia, visando, portanto, sua 
Revista Eletrônica de Direito Processual - REDP.

Rio de Janeiro. Ano 16. Volume 23. Número 1. Janeiro a Abril de 2022

Periódico Quadrimestral da Pós-Graduação Stricto Sensu em Direito Processual da UERJ

Patrono: José Carlos Barbosa Moreira (in mem.). ISSN 1982-7636. pp. 389-415

www.redp.uerj.br

reabilitação"41. Discutir o papel do cárcere exige uma reflexão profunda sobre a função dos presídios, das penas de reclusão e do próprio direito criminal, pois soluções que ainda estejam ancoradas na lógica do encarceramento, por melhor que sejam, podem estar fadadas ao fracasso ${ }^{42}$.

Pensar em políticas públicas punitivistas e voltadas ao encarceramento não faz cessar a fonte dos problemas, pois até que seja resolvido o problema da estrutura dos presídios,

“(...) isso não significará o desaparecimento de outras violações a direitos fundamentais que não serão resolvidos após o 'desbloqueio' político. (...) A principal violação de direitos humanos dos encarcerados envolve sua liberdade e não, necessariamente, seus direitos sociais; portanto, respostas orçamentárias seriam insuficientes para saná-las. As violações não cessam com a construção de mais e melhores presídios"43.

Essa reflexão, todavia, não implica dizer, automaticamente, que o aprimoramento das políticas públicas voltadas ao sistema carcerário ou a criação de novos presídios não seriam importantes para a superação do Estado de Coisas Inconstitucional existente no país. Implica dizer, tão somente, que verdadeiras mudanças nessa seara prescindiriam, também, de transformações culturais na forma de enxergar os direitos fundamentais e humanos dos $\operatorname{detentos}^{44}$.

\subsection{Bloqueios institucionais: a impopularidade e sub-representação dos presos versus resultados de longo prazo}

\footnotetext{
41 MAGALHÃES, Breno Baía. A incrível doutrina de um caso só: análise do estado de coisas inconstitucional na ADPF 347. Revista Eletrônica do Curso de Direito da UFSM, Santa Maria, RS, v. 14, n. 3, e32760, set./dez. 2019. ISSN 1981-3694. DOI: http://dx.doi.org/10.5902/1981369432760. Disponível em: https://periodicos.ufsm.br/revistadireito/article/view/32760 Acesso em: 14 set. 2020, p. 22.

42 MAGALHÃES, Breno Baía. A incrível doutrina de um caso só: análise do estado de coisas inconstitucional na ADPF 347. Revista Eletrônica do Curso de Direito da UFSM, Santa Maria, RS, v. 14, n. 3, e32760, set./dez. 2019. ISSN 1981-3694. DOI: http://dx.doi.org/10.5902/1981369432760. Disponível em: https://periodicos.ufsm.br/revistadireito/article/view/32760 Acesso em: 14 set. 2020, p. 22.

43 MAGALHÃES, Breno Baía. A incrível doutrina de um caso só: análise do estado de coisas inconstitucional na ADPF 347. Revista Eletrônica do Curso de Direito da UFSM, Santa Maria, RS, v. 14, n. 3, e32760, set./dez. 2019. ISSN 1981-3694. DOI: http://dx.doi.org/10.5902/1981369432760. Disponível em: https://periodicos.ufsm.br/revistadireito/article/view/32760 Acesso em: 14 set. 2020, p.24-25.

44 "Todo este quadro é ainda agravado pelo fato de este contexto de violação de direitos em que vivem os presos no Brasil, ser visto com indiferença social. Não são raras as constatações de que esta situação é largamente aceita por grande parcela da sociedade brasileira, que pautada no senso comum, acredita que os detentos realmente devem sofrer duras sanções e até mesmo penas cruéis." PEREIRA, Luciano Meneguetti. O Estado de Coisas Inconstitucional e a violação dos direitos humanos no sistema prisional brasileiro. Revista Interdisciplinar de Direitos Humanos, v. 5, n. 1, p. 167-190, 2017, p. 172.
} 
De acordo com o inciso III, do art. 15, da Constituição, enquanto durarem os efeitos da sentença criminal transitada em julgado o preso terá os seus direitos políticos suspensos. A perda dos direitos políticos tem o potencial de fazer com que os detentos sejam mal representados ou que seus interesses sequer sejam levados em consideração pelas instâncias majoritárias. Além disso, como mencionado no tópico anterior, grande parte da população brasileira acredita que os castigos desumanos sofridos no cárcere consistem em retribuição justa pelos crimes cometidos. Dessa forma, a opinião pública não aceitaria que as melhorias das instalações prisionais fossem questões prioritárias nos gastos públicos. Este ponto argumentativo, inclusive, foi utilizado pelo Ministro relator para demonstrar os dois bloqueios institucionais presentes no caso em questão ${ }^{45}$.

Assim, a impopularidade dos presos faria com que os políticos, salvo raras exceções, não reivindicassem recursos públicos a serem utilizados em um sistema carcerário voltado ao oferecimento de condições de existência digna aos detentos, afinal, questões criminais são capazes, de fato, de gerar paixões em níveis que outros temas e áreas do Direito não conseguem $^{46}$. De alguma forma, a ideia de que a tutela de condições dignas no cárcere é congruente com os direitos assegurados constitucionalmente não parece fazer sentido para uma sociedade que não tolera mais a criminalidade e a insegurança.

Marco Aurélio exemplifica a questão afirmando que:

\begin{abstract}
Comparem com a saúde pública: há defeitos estruturais sérios nesse campo, mas tem-se vontade política em resolvê-los. Não existe um candidato que não paute a campanha eleitoral, entre outros temas, na melhoria do sistema. Todos querem ser autores de propostas que elevem a qualidade dos serviços. Deputados lutam pela liberação de recursos financeiros em favor da população das respectivas bases e territórios eleitorais. A saúde pública sofre com déficits de eficiência, impugnados judicialmente por meio de um sem-número de ações individuais, mas não corre o risco de piora significativa em razão da ignorância política ou do desprezo social. O tema possui apelo democrático, ao contrário do sistema prisional. É difícil imaginar candidatos que tenham como bandeira de campanha a defesa da dignidade dos presos. A rejeição popular faz com que a matéria relativa à melhoria do sistema prisional enfrente o que os cientistas políticos chamam de "ponto cego
\end{abstract}

45 BRASIL. Supremo Tribunal Federal. Medida Cautelar na ADPF 347. ADPF $n^{\circ}$ 347. PARTIDO SOCIALISMO E LIBERDADE. Relator: Ministro Marco Aurélio. 09 de setembro de 2015. Disponível em: http://redir.stf.jus.br/paginadorpub/paginador.jsp?docTP=TP\&docID=10300665. Acesso em: 14 set 2020, p. 15.

46 BRASIL. Supremo Tribunal Federal. Medida Cautelar na ADPF 347. ADPF $n^{\circ}$ 347. PARTIDO SOCIALISMO E LIBERDADE. Relator: Ministro Marco Aurélio. 09 de setembro de 2015. Disponível em: http://redir.stf.jus.br/paginadorpub/paginador.jsp?docTP=TP\&docID=10300665. Acesso em: 14 set 2020, p. 15. 
Revista Eletrônica de Direito Processual - REDP.

Rio de Janeiro. Ano 16. Volume 23. Número 1. Janeiro a Abril de 2022

Periódico Quadrimestral da Pós-Graduação Stricto Sensu em Direito Processual da UERJ

Patrono: José Carlos Barbosa Moreira (in mem.). ISSN 1982-7636. pp. 389-415

www.redp.uerj.br

legislativo" (legislative blindspot): o debate parlamentar não a alcança ${ }^{47}$.

As questões levantadas pelo Ministro relator, dessa forma, seriam responsáveis por ensejar "pontos cegos" e bloqueios políticos, que só poderiam ser superados com a interferência do Supremo Tribunal Federal, vez que, em tese, não sofre interferência da opinião pública e exerce função tipicamente contramajoritária.

A impopularidade da população carcerária, bem como sua sub-representação no Parlamento, se somadas ao fato de que processos estruturais, na grande maioria das vezes, são caros e levam tempo para começarem a produzir resultados, pode não somente obstar o enfrentamento de um litígio estrutural em um processo desse mesmo cariz como, também, desencorajar a adoção de quaisquer medidas voltadas à superação das violações massivas e reiteradas a direitos no cárcere.

\subsection{Diálogos institucionais entre os Poderes}

Um ponto de importante destaque foi o reconhecimento de que o estágio ao qual havia se chegado, não poderia ser atribuído a um único e exclusivo Poder, e sim aos três: Executivo, Legislativo e Judiciário, e não somente os da União, mas, também, os dos Estados e do Distrito Federal, havendo problemas tanto de formulação e implementação de políticas públicas, quanto de interpretação e aplicação da lei penal, caracterizando uma verdadeira "falta de coordenação institucional"48.

Assim, apesar de muitos dos direitos violados serem assegurados na Lei ${ }^{\circ}$ 7.210/84 - Lei de Execução Penal - e na Lei Complementar no 79/94 - Lei do Fundo Penitenciário Nacional -, estar-se-ia diante de verdadeira omissão reiterada e persistente das autoridades públicas no cumprimento das obrigações estabelecidas em favor dos presos ${ }^{49}$ e um funcionamento deficiente do Estado como um todo.

47 BRASIL. Supremo Tribunal Federal. Medida Cautelar na ADPF 347. ADPF no 347 . PARTIDO SOCIALISMO E LIBERDADE. Relator: Ministro Marco Aurélio. 09 de setembro de 2015. Disponível em: http://redir.stf.jus.br/paginadorpub/paginador.jsp?docTP=TP\&docID=10300665. Acesso em: 14 set 2020, p. 15.

48 BRASIL. Supremo Tribunal Federal. Medida Cautelar na ADPF 347. ADPF n 347 . PARTIDO SOCIALISMO E LIBERDADE. Relator: Ministro Marco Aurélio. 09 de setembro de 2015. Disponível em: http://redir.stf.jus.br/paginadorpub/paginador.jsp?docTP=TP\&docID=10300665. Acesso em: 14 set 2020, p. 5. 49 BRASIL. Supremo Tribunal Federal. Medida Cautelar na ADPF 347. ADPF n 347 . PARTIDO SOCIALISMO E LIBERDADE. Relator: Ministro Marco Aurélio. 09 de setembro de 2015. Disponível em: http://redir.stf.jus.br/paginadorpub/paginador.jsp?docTP=TP\&docID=10300665. Acesso em: 14 set 2020 , p. 9 . 
A inércia, para o Tribunal, estaria caracterizada não somente quando ausente a legislação, mas, também, diante da inexistência de qualquer tentativa de modificação da situação, que não só configuraria um descaso com a situação como, também, propiciaria o agravamento desta. Diante de tal quadro, a solução seria envolver - numa atuação coordenada, mútua e complementar - o Legislativo, o Executivo e o Judiciário dos diferentes níveis federativos, e não somente um único órgão ou entidade ${ }^{50}$.

O Ministro designou o caso como sendo uma situação que envolve diretamente os chamados "litígios estruturais", caracterizando-os enquanto aqueles nos quais é necessária a correção ou criação de políticas públicas, a alocação de recursos orçamentários, ajustes e reestruturações institucionais e outras medidas que envolvem uma pluralidade de autoridades públicas.

Apesar do reconhecimento da necessidade de participação dos demais Poderes, o pontapé inicial do Supremo Tribunal Federal no sentido de dialogar com as instituições majoritárias responsáveis pelas violações ocorridas parece não ter fomentado um diálogo cooperativo, como era esperado, e isso não parece ter decorrido do fato de que o Tribunal não tomou medidas mais fortes e impositivas - utilizando-se de uma espécie de "strong judicial review" $" 51$ - ou da falta de um pedido final dialógico na petição do PSOL, e sim da indisponibilidade institucional para o diálogo por parte dos requeridos, colocando em dúvida a possibilidade de juízes, por meio do Direito, serem capazes de transformar a realidade social.

\section{Conclusão}

Diante de cenários calamitosos que infringem direitos fundamentais e comprometem a vida digna dos destinatários primários das promessas constitucionais, a provocação da jurisdição por meio de um pedido estrutural aparece enquanto possível alternativa aos cenários de bloqueio político, à inércia das instâncias majoritárias e à manutenção do status

50 BRASIL. Supremo Tribunal Federal. Medida Cautelar na ADPF 347. ADPF no 347. PARTIDO SOCIALISMO E LIBERDADE. Relator: Ministro Marco Aurélio. 09 de setembro de 2015. Disponível em: http://redir.stf.jus.br/paginadorpub/paginador.jsp?docTP=TP\&docID=10300665. Acesso em: 14 set 2020, p. 8 . 51 TUSHNET, Mark V.. Weak Courts, Strong Rights: Judicial Review and social welfare rights in comparative constitucional law. Princeton: Princeton University Press, 2008, p. 21. 
quo vigente.

Nesse sentido, após delineada a ideia de "ativismo dialógico", foram apresentadas duas propostas de posturas que podem (e devem) ser adotadas pelos magistrados quando estes são provocados a enfrentar petições com pedidos estruturais. A primeira foi a da jurista Susan Sturm, que defende a participação, o respeito à teoria da separação dos poderes, a imparcialidade, a fundamentação adequada das decisões e a remediação. A segunda, foi a da professora Susana Henriques da Costa, que argumenta ser necessário que o magistrado aja de maneira consequencialista, estratégica e mediadora.

Após a exposição teórica, passou-se à análise da ADPF 347, que versou acerca da inconstitucionalidade do sistema carcerário brasileiro e da consequente insustentabilidade das condições precárias em que se encontravam os detentos nos presídios do país. Foram observados, nesse sentido, três pontos importantes, na tentativa de compreender se o voto do ministro relator buscou engajar o Supremo Tribunal Federal em um diálogo com as instâncias políticas: 1) complexidade, experimentalismo e cultura punitivista; 2) a impopularidade e sub-representação dos presos versus resultados de longo prazo; e 3) a necessidade de diálogo entre os Poderes em detrimento do ECI prisional ser decorrente da falta de coordenação entre eles.

Ultrapassada essa fase, verificou-se que: a) a complexidade e experimentalismo parecem agravar o cenário dos detentos no país. Isso porque processos estruturais são caros, demorados, e, em geral, demandam diversas tentativas de medidas até que alguma melhora seja vista. Não parece ser interesse dos brasileiros que tempo e dinheiro sejam investidos no aprimoramento das condições carcerárias daqueles que a população, em grande parte, considera serem merecedores das atrocidades com as quais têm que lidar diariamente; b) a impopularidade e sub-representação dos presos aparenta contraditar a necessidade imediatista das instituições majoritárias de produzirem resultados concretos, dentro de seus mandatos, a fim de garantir reeleições futuras e de agradar seus eleitores. Ademais, a indisponibilidade desses atores em atuarem em prol do grupo marginalizado em questão parece não os afetar diretamente, uma vez que os presos têm seus direitos políticos suspensos enquanto durar a pena; e c) a tentativa de diálogo com os Poderes (também) responsáveis pelo ECI no sistema carcerário, por parte do STF, demonstra que não havia interesse 
institucional ${ }^{52}$ em resolver a questão em pauta e, consequentemente, em estabelecer um diálogo cooperativo com o Poder Judiciário.

O primeiro passo para o desenvolvimento de um processo estrutural, de fato, é a adoção de uma postura dialógica por partes dos magistrados - e, de preferência, que respeitem todos ou, pelo menos, alguns dos critérios estabelecidos por Susan Sturm e Susana Henriques da Costa -, mas ela, por si só, não garante bons resultados ou sequer quaisquer resultados. Isso ocorre por, pelo menos, dois motivos. O primeiro é que uma decisão aparentemente dialógica pode não representar uma verdadeira disposição do Tribunal em dialogar com os demais ramos do poder estatal. Pode retratar, ao revés, uma manobra estratégica para não deixar de responder a uma questão que diz respeito diretamente à violação sistemática de direitos fundamentais sem, contudo, comprometer a autoridade da instituição. Assim, o STF mostra-se sensível à proteção de direitos de grupos vulneráveis exercendo a função contramajoritária para a qual foi primordialmente designado - e, ao mesmo tempo, observa o backlash de sua decisão, movimentando-se, posteriormente, de acordo com a reação das instâncias majoritárias e da população sobre um tema (política e socialmente) custoso, não incorrendo no risco de comprometer sua autoridade institucional.

O segundo é que, ainda que o Tribunal esteja, de fato, comprometido com a mudança do quadro de violações massivas e reiteradas a direitos fundamentais, as mudanças só vão acontecer se houver disposição política em efetivá-las, pois dificilmente o direito, sozinho, é capaz de transformar cenários calamitosos que perduram há décadas por razões inerentes à própria cultura do país. Transformações profícuas, portanto, dependem mais dos contextos sócio-políticos em que estão inseridos do que da postura judicial adotada.

\footnotetext{
52 Sobre a ADPF 347, Vitorelli argumenta que esta foi um caso de litígio estratégico com pedido estrutural; ou seja, o caso visava a produção de um novo precedente ou uma nova compreensão do direito, bem como uma reforma no modo como as instituições que causavam a violação a direitos atuavam ou deixavam de atuar. Isso porque, segundo o autor, a requisição de que fosse declarado um ECI do sistema carcerário no país em nada mudaria a situação fática dos presos, mas poderia ser capaz de mobilizar a comunidade jurídica e as autoridades relacionadas ao tema, pois a obtenção de uma declaração, pelo tribunal mais alto do país, de que algo está errado, é uma estratégia importante de mobilização de forças. O autor continua sua linha de argumentação alegando que a petição inicial da Arguição de Descumprimento de Preceito Fundamental acabou envolvendo metas tão abrangentes e tão difíceis de serem realizadas, que é mais provável que a intenção da própria ADPF tenha sido mais simbólica que prática. Vitorelli finaliza argumentando que a construção de pedidos demasiadamente distantes da realidade, com providências altamente complexas e conflituosas, como ocorreu no caso da ADPF 347, pode atrair descrédito para o autor, sem o resultado estratégico objetivado e sem benefícios diretos para a situação litigiosa, que poderiam ser viáveis se o pedido elaborado fosse mais factível. VITORELli, Edilson. Processo Civil Estrutural: Teoria e Prática. Salvador: Juspodium, p. 263-265.
} 
Isso não quer dizer, entretanto, que demandas estruturais não devam ser ajuizadas, mas que, nem sempre, repercutirão o efeito pretendido. Mesmo quando não são capazes de provocar mudanças substanciais, entretanto, a judicialização desses casos contribui para chamar a atenção do Poder Judiciário, dos demais órgãos públicos, da população, da mídia, da academia e da sociedade civil organizada, para as violações de direitos fundamentais que, anteriormente, passavam despercebidas ou não eram tratadas como questões "de direito". Somente com esforços contínuos, de fato, é que a Constituição se transformará numa "verdade viva" 53 .

\section{REFERÊNCIAS:}

ALBUQUERQUE, Felipe. SERAFIM, Matheus. A importância da participação pública nos processos estruturais: contribuições da teoria normativa de Susan Sturm. Revista Estudos Institucionais, v. 6, n. 2, mai./ago. 2020, p. 643-665.

BRASIL. Supremo Tribunal Federal. Medida Cautelar na ADPF 347. ADPF no 347. PARTIDO SOCIALISMO E LIBERDADE. Relator: Ministro Marco Aurélio. 09 de setembro de 2015.

Disponível em: http://redir.stf.jus.br/paginadorpub/paginador.jsp?docTP=TP\&docID=10300665. Acesso em: 14 set. 2020.

FISS, Owen. To make the Constitution a Living Truth. In: ARENHART, Sérgio Cruz; JOBIM, Marco Félix (org.). Processos estruturais. Salvador: JusPodivm, 2017, p. 583-606.

CAMPOS, Carlos Alexandre de Azevedo. Dimensões do Ativismo Judicial do STF. Rio de Janeiro: Forense, 2014.

COLOMBIA. Corte Constitucional Colombiana. Sentença T-25/04. Abel Antonio Jaramillo e outros e Red de Solidaridad Social e outros. Relator: Magistrado Manuel José Cepeda Espinosa. Bogotá, COLÔMBIA, 24 de janeiro de 2004. Disponível em: https://www.corteconstitucional.gov.co/relatoria/2004/t-025-04.htm. Acesso em: 14 set. 2020

\footnotetext{
53 FISS, Owen. To make the Constitution a Living Truth. In: ARENHART, Sérgio Cruz; JOBIM, Marco Félix (org.). Processos estruturais. Salvador: JusPodivm, 2017, p. 606.
} 
COSTA, Susana Henriques da. A Imediata Judicialização dos Direitos Fundamentais Sociais e o Mínimo Existencial: Relação Direito e Processo. In: GRINOVER, Ada Pellegrini; WATANABE, Kazuo e COSTA, Susana Henriques da (org.) O processo para solução de conflitos de interesse público, São Paulo: Juspodivm, 2017, p. 397-419.

HIRSCHL, Ran. Towards juristocracy: The origins and consequences of the constitutionalism. Cambridge: Harvard University Press, 2004.

HORTA, Ricardo Lins. Por que existem vieses cognitivos na Tomada de Decisão Judicial? A contribuição da Psicologia e das Neurociências para o debate jurídico. Revista Brasileira de Políticas Públicas, v. 9, n. 3, p. 84-122, 2019.

LIMA, Flavia Danielle Santiago; FRANÇA, Eduarda Peixoto da Cunha. Ativismo dialógico $\mathrm{x}$ bloqueios institucionais: limites e possibilidades do controle jurisdicional de políticas públicas a partir da Sentencia T-025/04 da Corte Colombiana. Argumenta Journal Law, n. 31, p. 209-243, jul./dez., 2019.

LIMA, Flávia Danielle Santiago Lima. Jurisdição constitucional e política: ativismo e autocontenção no STF. Curitiba: Juruá, 2014.

LIMA, Flávia Danielle Santiago; GOMES, José Mário Wanderley; BARBOSA, Leon Victor Queiroz. Exploring the Wonderful Mystery of Time: Lack of Grounds in the Constitutional Judicial Review as an Evidence of Passive Virtues in the Brazilian Supreme Court (STF). Revista Direito e Justiça: Reflexões Sociojurídicas, v. 18, n. 30, 2018, p. 21-36.

MAGALHÃES, Breno Baía. A incrível doutrina de um caso só: análise do estado de coisas inconstitucional na ADPF 347. Revista Eletrônica do Curso de Direito da UFSM, Santa Maria, RS, v. 14, n. 3, e32760, set./dez. 2019. ISSN 1981-3694. DOI: http://dx.doi.org/10.5902/1981369432760.

Disponível em: https://periodicos.ufsm.br/revistadireito/article/view/32760 Acesso em: 14 set. 2020.

NUNES, Dierle. Colegialidade corretiva, precedentes e vieses cognitivos: algumas questões do CPC-2015. Revista do TRF3-Ano XXVII-n, 2016, p.61-81.

PEREIRA, Luciano Meneguetti. O Estado de Coisas Inconstitucional e a violação dos direitos humanos no sistema prisional brasileiro. Revista Interdisciplinar de Direitos Humanos, v. 5, n. 1, 2017, p. 167-190.

SCOTT, Joanne; STURM, Susan. Courts as catalysts: re-thinking the judicial role in new 
governance. Columbia Journal of European Law, v. 13, 2006, p. 565-594.

STURM, Susan P. A normative theory of public law remedies. Georgetown Law Journal, v. 79, 1991, p. 1357-1445.

TUSHNET, Mark V.. Weak Courts, Strong Rights: Judicial Review and social welfare rights in comparative constitucional law. Princeton: Princeton University Press, 2008.

VITORELLI, Edilson. Litígios Estruturais: decisão e implementação de mudanças socialmente relevantes pela via processual. In: ARENHART, Sérgio Cruz; JOBIM, Marco Félix (Org.). Processos Estruturais. Salvador: Juspodivm, 2017. p. 369-422.

VITORELLI, Edilson. Processo Civil Estrutural: Teoria e Prática. Salvador: Juspodium. 